\title{
Adsorption of phenol on natural clay
}

\author{
M. Djebbar · F. Djafri $\cdot$ M. Bouchekara $\cdot$ \\ A. Djafri
}

Received: 15 April 2011/Accepted: 2 February 2012/Published online: 7 March 2012

(C) The Author(s) 2012. This article is published with open access at Springerlink.com

\begin{abstract}
Natural clay being locally abundant and cheap material in Algeria can be easily activated to become a promising adsorbent for phenol removal from aqueous solution. The natural clay before and after activation was characterized using XRD and IR techniques. The effects of various experimental parameters, such as initial phenol concentration, temperature, $\mathrm{pH}$, contact time, and adsorbent dose on the adsorption extent were investigated. Langmuir adsorption model was used for the mathematical description of the adsorption equilibrium and the equilibrium data fixed very well with this model. The activated natural clay had the monolayer adsorption capacity equal to $15 \mathrm{mg} / \mathrm{g}$ at $\mathrm{pH}$ value of 5.0 and $23^{\circ} \mathrm{C}$; adsorption measurements show that the process is very fast and physical in nature. The extent of the phenol removal increased with decrease in the initial concentration of the phenol and contact time of solution. The results showed that as the amount of the adsorbent was increased, the percentage of phenol removal increased accordingly. Thermodynamic parameters showed that the adsorption of phenol on activated natural clay was exothermic.
\end{abstract}

Keywords Phenol - Activated clay · Adsorption isotherm . Thermodynamic parameters $\cdot$ Montmorillonites ·

Adsorbent $\cdot \mathrm{X}$-ray diffraction

M. Djebbar $(\bowtie) \cdot$ M. Bouchekara

Faculty of Science and Technology, University of Mascara, P.O. Box 763, 29000 Mascara, Algeria

e-mail: djebbar_mustapha@yahoo.fr

F. Djafri · A. Djafri

Faculty of Science, University of Oran,

P.O. Box 1505, El-Menouer, 31000 Oran, Algeria

\section{Introduction}

Many wastewaters contain significant levels of organic contaminants, which are toxic or otherwise undesirable because they create odor, unsightly color, foaming, etc. (Aygiin et al. 2003).Among the different organic pollutants of aquatic ecosystems, phenols, especially the chlorinated ones, are considered as priority pollutants since they are harmful to plants, animals, and human, even at low concentrations (Apha et al. 2006).

For the removal of aqueous dissolved organic pollutants the advanced water treatment process like adsorption onto natural clay is considered to be the most effective and reliable method. Natural clay either in granules or powder form has good capacity for the adsorption of organic molecules (Hassani et al. 2008; Aghamohammadi et al. 2007). They have ability to attract to their surface soluble materials such as phenol from solution.

Literature shows the use of natural clay made from various low-cost materials like straw,automobile tyres, fly ash, coal reject, sewage sludge, begasse, fertilizer waste, saw dust, etc. for phenol adsorption. (Rengaraj et al. 2002a, b) used activated carbon prepared from rubber seed coat for phenol adsorption. Different porous materials like activated carbon cloth, activated carbon fiber, Ca-alginate beads, diatomaceous earth, denatured biomass, chitosan material (Annadurai et al., 2000), Na- Alginate, ion exchange resin, clay, etc. have been used for adsorption. In designing adsorption system it is necessary to know the adsorption capacity of an adsorbent which is characterized by the isotherm study. There is continuous diffusion of solute from the liquid into the solid surface and back diffusion of solute into the liquid. At equilibrium the solute remaining in solution are in dynamic equilibrium with that of the surface. (Kumar et al. 2007) have conducted detailed literature survey of the various adsorption isotherms. 
They are some literature references concerning the phenol adsorption on organobentonite (Juang et al. 2002; Vianna et al. 2004), but in our opinion they need further verification, especially in respect to the $\mathrm{pH}$ influence on the phenol uptake by adsorbent.

The prime objectives of the present investigation were to conduct the batch sorption tests, which include determination of sorption kinetics and isothermal adsorption capacity of the sorbent and to assess the effect of ( $\mathrm{pH}$ was 5.0) on the removal of phenol from synthetic waste water (Hall et al. 1996; Alkaram et al. 2009).

\section{Materials and methods}

\section{Samples}

The clay used in this study was an Algerian montmorillonite, a bentonite type from Roussel in Maghnia, N.W. Algeria. It was supplied by ENOF Chemical Ltd., Research Company of "non ferreux", Algeria. For these materials the cation exchange capacity $(\mathrm{CEC})=90$ was assumed.

\section{Treatment and purification procedure}

The natural clays were washed several times with distilled and deionised water and were completely dispersed in water. After $7 \mathrm{~h}$ at rest, the dispersion was centrifuged for $1 \mathrm{~h}$ at 2,400 rpm. The size of the clay particles obtained was $<2 \mu \mathrm{m}$.

\section{Preparation of Na-montmorillonite}

These clay particles were dispersed in water and heated at $75^{\circ} \mathrm{C}$ in the presence of a solution composed of the sodium salts of bicarbonate $(1 \mathrm{M})$, citrate $(0.3 \mathrm{M})$, and chloride (2 M) (Pusino et al. 1989; Robert and Tessier 1974). The purpose of this operation was to eliminate inorganic and organic compounds, aluminium found in the inter-layer spaces and various free cations. Carbonates were removed by treatment with $\mathrm{HCl}(0.5 \mathrm{M})$ and chloride was eliminated after several washings. The organic matter was eliminated completely by treatment with $\mathrm{H}_{2} \mathrm{O}_{2}(30 \% \mathrm{v} / \mathrm{v})$ at $70^{\circ} \mathrm{C}$. The purified clay was dried at $110^{\circ} \mathrm{C}$, and then saturated with sodium $\left(\mathrm{Na}^{+}\right)$. To ensure complete transformation into the sodium form, all samples were washed several times with a $\mathrm{NaOH}$ solution (1 M).

Preparation of Na-montmorillonite

Total CEC and the external CEC (ECEC) were measured according to Haggerty and Bowman method (Haggerty and Bowman 1994).
The dried natural clay and activated clay were characterized for CEC by ammonium acetate method. The experiment have been carried out minimum ten times to ascertain the values and these are reproducible. The compositions of these clays were determined by chemical method. The TG analysis of natural clay and activated clay was done with METTLER TG50, up to $900^{\circ} \mathrm{C}$ with a heating rate of $20^{\circ} \mathrm{C} / \mathrm{min}$ in air.

One gram of $<2 \mu \mathrm{m}$ purified montmorillonite fraction, sodium form, was treated with the required amount of complex according to the following derived equation:

$x \mathrm{~g}$ of complex needed

$$
=\frac{\text { meq of clay } / 100 \mathrm{~g} \times \mathrm{wt}(\mathrm{kg}) \text { of clay used } \times \mathrm{RMM}}{\text { Activity of the RMM } \times \text { Valency of } \mathrm{RMM}}
$$

$x \mathrm{~g}$ of complex needed $=$ meq of clay/100g $\times$ wt $(\mathrm{kg})$ of clay used $\times$ RMM of the complex.

where the activity of the complex is the \% purity of complex; valency of the complex is the charge on the salt and meq of montmorillonite $=90$.

Purity of the natural clay samples before and after activation was tested by IR spectral analysis. An IR transmittance spectrum of the ground samples was obtained in the 4,000-400 $\mathrm{cm}^{-1}$ range with Perkin-Elmer FT 1720 spectrometer.

Purity of the natural clay samples before and after activation was determined by the analysis of the X-ray diffraction (XRD) spectra, which involved the identification and semiquantification of the peak characterstics of the minerals present. A Philips diffractometer with D5000 Ni-filtered $\mathrm{CuK} \alpha$ radiation was used 1,5406 $\AA$. Natural clay samples before and after activation both randomly and with preferred orientation were scanned over the interval $5-80^{\circ} 2 \theta$ at scanning speeds of $0.03 \% \mathrm{~s}$.

\section{Results and discussion}

\section{Natural clay characterization}

\section{$X$-ray diffraction}

X-ray diffraction patterns were obtained using a Philips PW 1730 diffractometer equipped with $\mathrm{Cu}-\mathrm{K} \alpha$ radiation $(40 \mathrm{kV}, 30 \mathrm{~mA})$. The X-ray diffraction patterns of the sample clay confirms the characteristics of montmorillonite type. It shows quartz impurities, residues of "feldspath".

The iron is present both as divalent and trivalent cations and it is believed that the presence of iron hinders the exchange of cation as well as expansion of d-spacing upon organophilization. Therefore, the amount of iron was reduced both in natural clay and activated clay was treated 
to remove excess iron, which is present as cations between the clay platelets. The characteristic properties of natural clay and activated clay for CEC increased to $65-81 \mathrm{meq} /$ $100 \mathrm{~g}$ from $81-100.7 \mathrm{meq} / 100 \mathrm{~g}$. This proves the above fact that upon removal of iron from clay, the total cation exchange capacity of clay increases.

This result is also supported by the TGA analysis of organoclay from natural clay and activated clay. The TG analysis of natural clay, after being submitted to above treatment indicated a mass loss of $1.2 \%$ up to $200^{\circ} \mathrm{C}$, due to dehydration and a mass loss of $6 \%$ from 200 to $800^{\circ} \mathrm{C}$, which can be attributed to dehydroxylation (Fig. 1).

The differential thermal curve of activated clay shows three peaks (Fig. 2), viz., (a) the free water region in the temperature below $200^{\circ} \mathrm{C}$; (b) the region where organic substances evolve in the temperature range $200-500^{\circ} \mathrm{C}$, and the structural water in the temperature range $500-800^{\circ} \mathrm{C}$.

The TG curves for activated clay with different concentrations of the alkyl ammonium salt is shown in Fig. 3. The comparison of thermograms of natural clay (a) with that of activated clay by sodium reveals the removal of

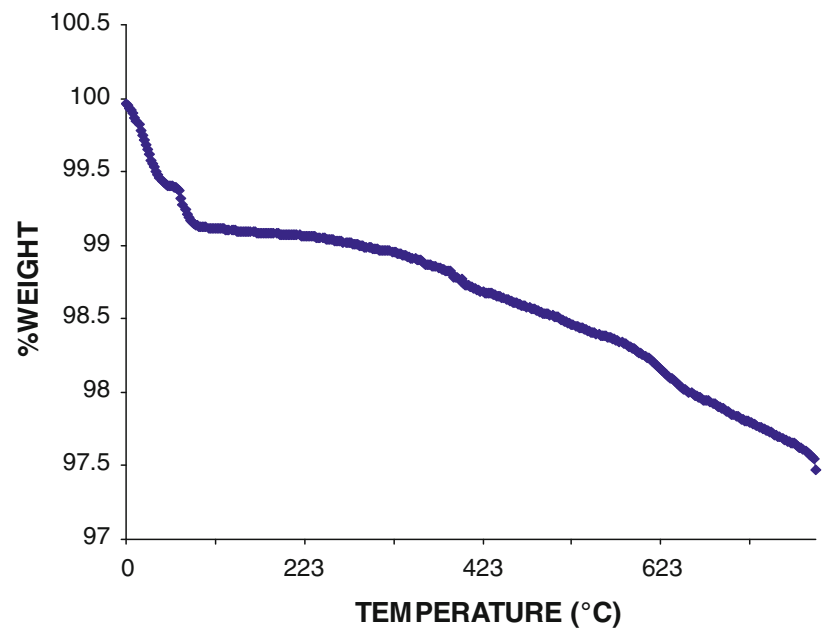

Fig. 1 TGA curve of natural clay

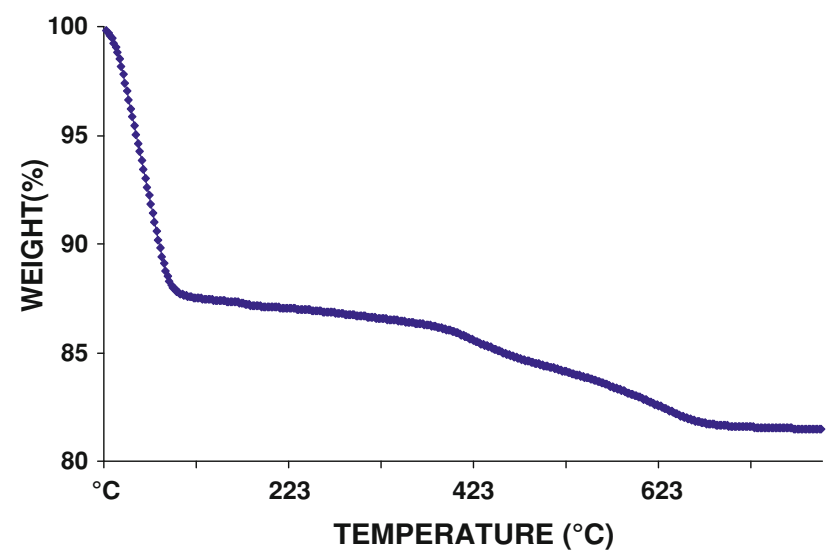

Fig. 2 TGA curve of activated clay

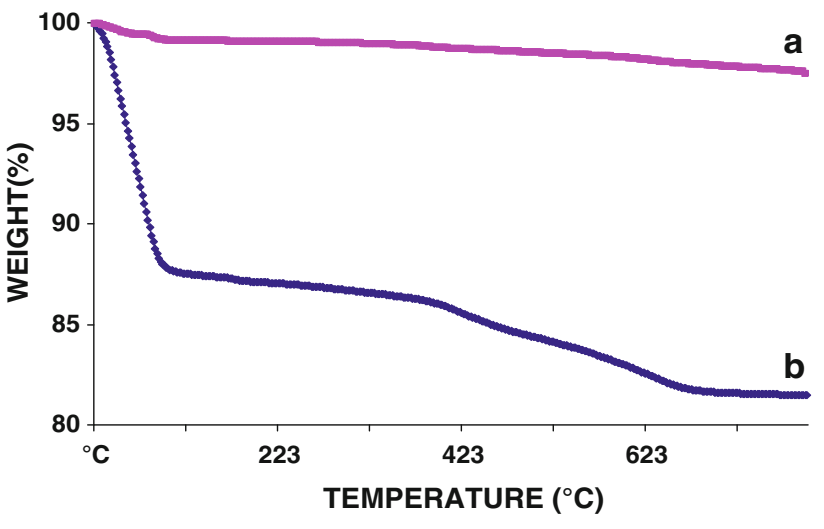

Fig. 3 TGA curve of: $a$ natural clay, $b$ modified clay

incorporated organic compounds. The loss is more in curve (b), because of high salt concentration CEC of clay, which is optimum amount of alkyl ammonium salt adsorption between intergalleries of clay.

Results of the X-ray diffraction analysis for natural and activated clay are shown in Fig. 4. Figure 4 clearly shows that the d-spacing of clay increased from 10.27 to $12.11 \AA$, which could be attributed to the activated clay. Quartz (reflection at $d=2.89 \AA, 2 \theta=35.97^{\circ}$ ) and calcite (reflection at $d=2.89 \AA, 2 \theta=35.97^{\circ}$ ) are the major impurities. The purified sample with Na-exchange shows the position of the 001 (reflection at $12.11 \AA, 2 \theta=5.37^{\circ}$ ) characterstics of sodium and kaolinite (reflection at $d=5.41 \AA, 2 \theta=19.03^{\circ}$ ).

\section{Infrared spectroscopy study}

The IR spectra of the clay samples were recorded over the spectral range $400-4,000 \mathrm{~cm}^{-1}$. In fact, IR techniques have been used by many researchers for identification of natural clay minerals (Hajjaji et al. 2001).The obtained characteristic bands of kaolinite appeared at 3,618.67, 3,641.59, $1,100.39,907.602, \quad 830.38, \quad 758.355, \quad 521.24$, and $456.84 \mathrm{~cm}^{-1}$ (Madejova 2003). The high intensity of the peak appearing at $1,100.78 \mathrm{~cm}^{-1}$ is an indication of the large amount of this mineral in the sample. The band at $1,100.78 \mathrm{~cm}^{-1}$ is attributed to $\mathrm{Si}-\mathrm{O}$ stretching. The bands at $830.38 \mathrm{~cm}^{-1}$ and $521.24,456.84 \mathrm{~cm}^{-1}$ are assigned to $\mathrm{Si}-\mathrm{O}-\mathrm{Al}$ and $\mathrm{Si}-\mathrm{O}-\mathrm{Mg}, \mathrm{Si}-\mathrm{O}-\mathrm{Fe}$ and bending vibrations, respectively. This indicated that most part of the layer charge resulted from trivalent $\left(\mathrm{Al}^{3+}, \mathrm{Fe}^{3+}\right)$ to bivalent $\left(\mathrm{Mg}^{2+}\right)$ ion substitution in the octahedral sheet. These functional groups are present in silicate minerals such as kaolinite and montmorillonite. The band observed at $3,412.41 \mathrm{~cm}^{-1}$ is assigned to stretching vibrations of adsorbed water molecules. Another characteristic band for bending vibrations of adsorbed water usually appears at $1,650-1,600 \mathrm{~cm}^{-1}$ as a medium band. The stretching 
Fig. 4 X-ray diffraction patterns of the natural clay and the activated clay
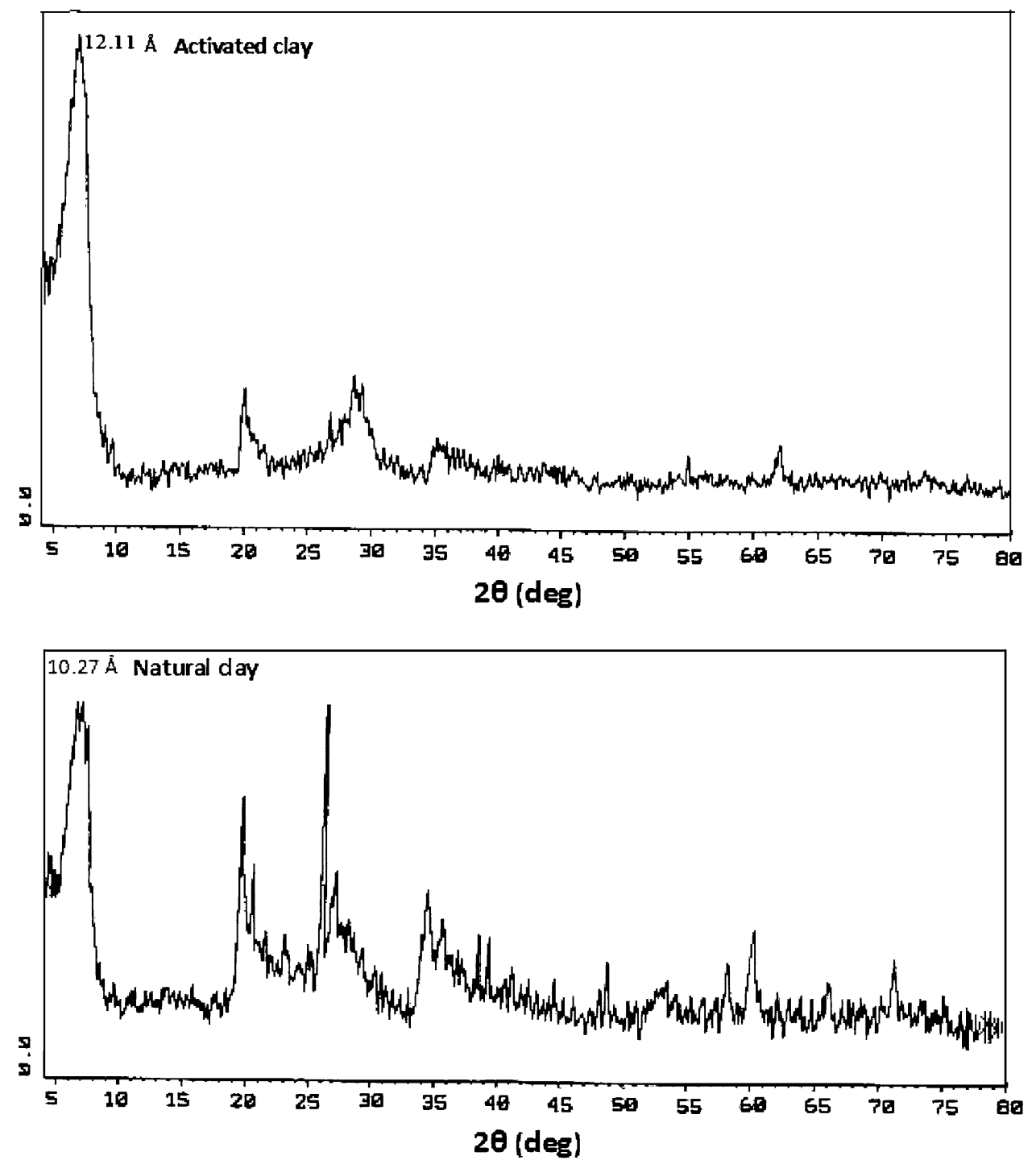

vibrations of the surface hydroxyl groups ( $\mathrm{Si}-\mathrm{Si}-\mathrm{OH}$, or $\mathrm{Al}-\mathrm{Al}-\mathrm{OH})$ are found at $3,618.67$ and $3,641.59 \mathrm{~cm}^{-1}$. The characteristic bands of montmorillonite-Na were observed at $1,036.39$ and $456.20 \mathrm{~cm}^{-1}$ (Madejova 2003). The high intensity of the peak appearing at $1,036.39 \mathrm{~cm}^{-1}$ is an indication of the large amount of this mineral in the sample. The band at $1,036.39 \mathrm{~cm}^{-1}$ is attributed to $\mathrm{Si}-\mathrm{O}$ stretching. The band at $456.20 \mathrm{~cm}^{-1}$ is assigned to $\mathrm{Si}-\mathrm{O}-\mathrm{Si}$ bending vibrations (Gadsden 1975).

Figures 5, 6 present the spectra IR of natural and activated clay. The examination of these spectra reveals following characteristic absorption bands.

\section{Experimental procedure}

Adsorption experiments were carried out by agitating $100 \mathrm{mg}$ of natural clay with $100 \mathrm{~mL}$ of phenol solution of desired concentration and $\mathrm{pH}$ at $180 \mathrm{rpm}, 23^{\circ} \mathrm{C}$ in a thermostated mechanical shaker (ORBITEK, Chennai). Concentration of phenol was estimated spectrophotometrically by monitoring the absorbance at $270 \mathrm{~nm}$ using UV-Vis spectrophotometer (Hitachi, model 8543).

The ( $\mathrm{pH}$ was 5.0) measured using $\mathrm{pH}$ meter (3151 MWT, Germany). The samples were withdrawn from the shaker at predetermined time intervals and the phenol solution was separated from the adsorbent by centrifugation at $1,000 \mathrm{rpm}$ for $15 \mathrm{~min}$. The absorbance of supernatant solution was measured. Effect of $\mathrm{pH}$ was studied by adjusting the $\mathrm{pH}$ of phenol solutions using dilute $\mathrm{HCl}$ and $\mathrm{NaOH}$ solutions. Effect of adsorbent dosage was studied by agitating $100 \mathrm{~mL}$ of $5 \mathrm{mg} / \mathrm{L}$ phenol solutions with different adsorbent doses (1-5 mg) at equilibrium time.

The amounts of phenol sorbed by the adsorbent were calculated using the following equation (Denizli et al. 2005; Freundlich 1926). 


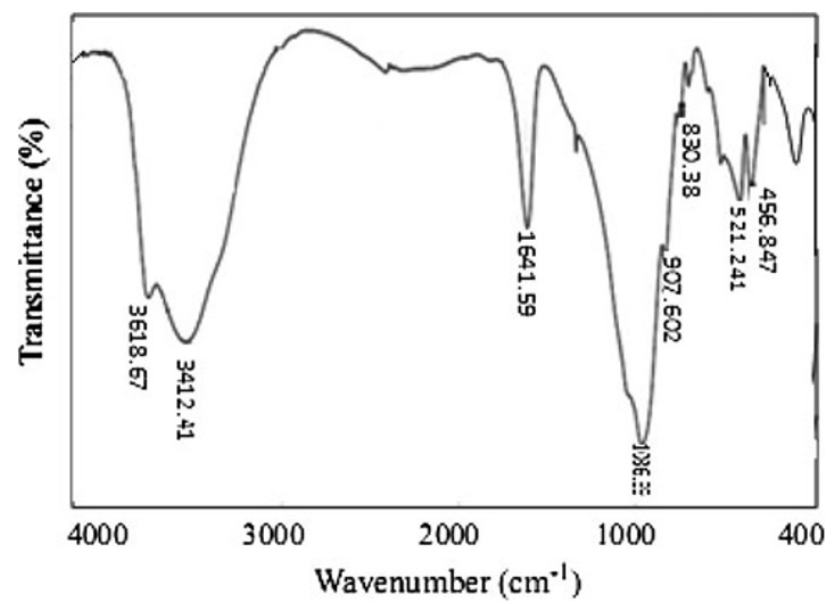

Fig. 5 FTIR spectra of activated clay

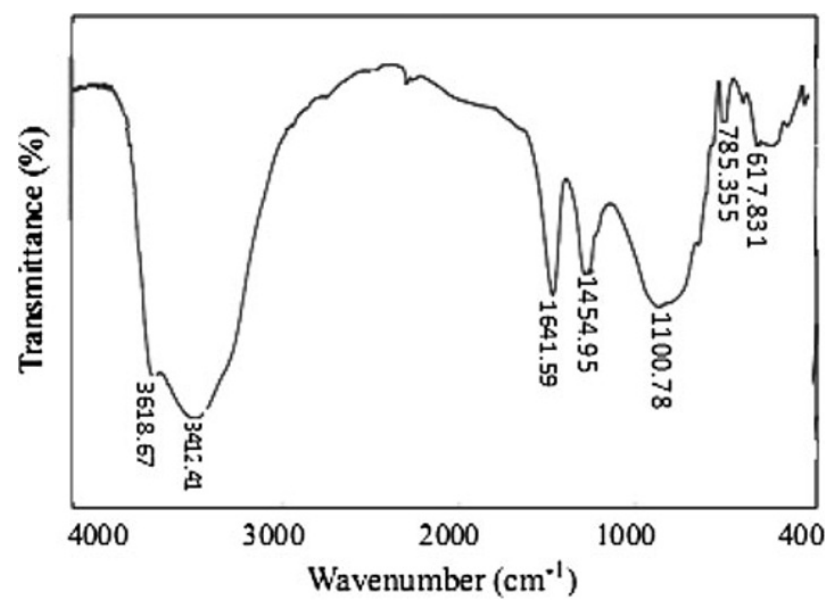

Fig. 6 FTIR spectra of natural clay

$Q=\left(C_{\mathbf{i}}-C_{\mathbf{e}}\right) V / M$

where $Q(\mathrm{mg} / \mathrm{g})$ is the amount of phenol sorbed by natural clay, $C_{0}$ and $C_{\mathrm{e}}(\mathrm{mg} / \mathrm{L})$ are the initial and equilibrium liquid-phase concentration of phenol, respectively, $V(\mathrm{~L})$ the initial volume of phenol solution and $M(\mathrm{~g})$ the weight of the natural clay.

The adsorption (the percentage) with the $C_{\mathrm{i}}$ and $C_{\mathrm{e}}$ was calculated as the following equation:

$\%$ Adsorption $=\left[\left(C_{\mathrm{i}}-C_{\mathrm{e}}\right) / C_{0}\right] \times 100 \%$

\section{Adsorption isotherm}

Freundlich isotherm model

There are several models that have been reported in the literature to describe experimental data as adsorption isotherms. Analysis of the isotherm data is important in order to develop equations that represent the results which could be used for design purposes. In this study two models (Freundlich and Langmuir) were used to describe the relationship between the amount of phenol adsorbed and its equilibrium concentration for all adsorbents.

Freundlich isotherm is expressed as follow:

$Q_{\mathrm{e}}=K_{\mathrm{F}} \sqrt[n]{\left(C_{\mathrm{e}}\right)}$

where, $Q_{\mathrm{e}}$ is the amount adsorbed at equilibrium $(\mathrm{mg} / \mathrm{g})$, $C_{\mathrm{e}}$ is equilibrium concentration of the adsorbate $(\mathrm{mg} / \mathrm{L})$, and $K$ and $1 / n$ are the Freundlich constants related to adsorption capacity and adsorption intensity, respectively of the adsorbent. The values of $k$ and $1 / n$ can be obtained from the intercept and slope respectively of the linear plot of $\ln Q_{\mathrm{e}}$ versus $\ln C_{\mathrm{e}}$ (Langmuir 1918; Ibrahim and Abushina 2008). The linear form of the Freundlich isotherm model is given by the following relation:

$\ln Q_{\mathrm{e}}=\ln K_{\mathrm{F}}+1 / n \ln C_{\mathrm{e}}$

\section{Langmuir isotherm model}

Langmuir isotherm is expressed as follow :

$Q_{\mathrm{e}}=\frac{Q m K C_{\mathrm{e}}}{1+K C_{\mathrm{e}}}$

where, $Q_{\mathrm{e}}$ is the amount adsorbed at equilibrium $(\mathrm{mg} / \mathrm{g}), C_{\mathrm{e}}$ is equilibrium concentration of the adsorbate $(\mathrm{mg} / \mathrm{L})$, and $Q_{\mathrm{m}}(\mathrm{mg} / \mathrm{g})$ and $K(\mathrm{~L} / \mathrm{mg})$ are the Langmuir constants related to the maximum adsorption capacity and the energy of adsorption, respectively. These constants can be evaluated from the intercept and slope of the linear plot experimental data of $1 / Q_{\mathrm{e}}(\mathrm{g} / \mathrm{mg})$ versus $1 / C_{\mathrm{e}}(\mathrm{L} / \mathrm{mg})($ Giles and Nakhwa 1962; Lin and Cheng 2002).

The linear form of the Langmuir isotherm model can be represented by the following relation:

$\frac{1}{Q_{\mathrm{e}}}=\frac{1}{Q_{\mathrm{m}}}+\frac{1}{K Q_{\mathrm{m}}} \times \frac{1}{C_{\mathrm{e}}}$

The linearized Freundlich and Langmuir adsorption isotherms of each adsorbent for phenol are shown in Figs. 7, 8, respectively. The Langmuir and Freundlich constants are listed in Table 1.

Based on values of correlation coefficient, $R^{2}$ summarized in Table 1, the adsorption of phenol on activated and natural clay was described well by both Langmuir and Freundlich models. Both homogeneous and heterogeneous adsorption energy took place during the process. On the other hand, the, Freundlich and Langmuir models was the best model to explain the adsorption behavior phenol on activated and natural clay.

The Freundlich model was the best to describe the adsorption equilibrium data at low concentrations and at different temperatures with $R^{2}=0.991$ (Eq. 3), implying 


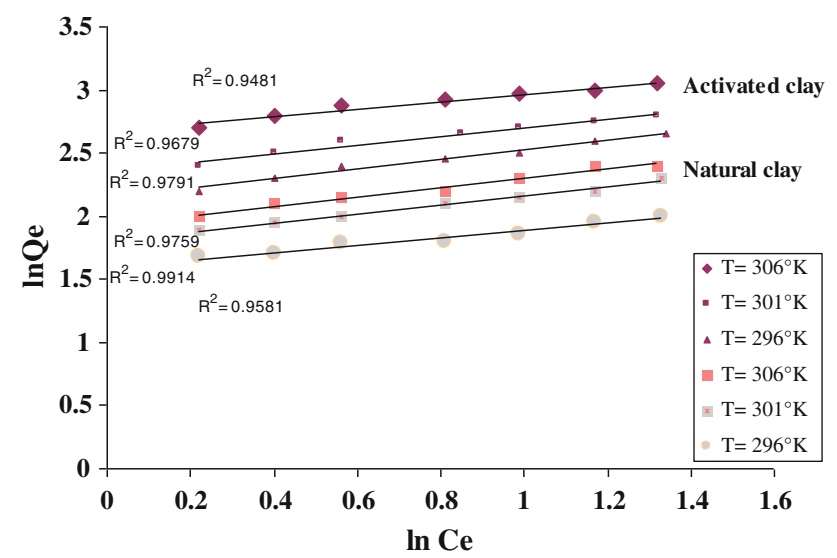

Fig. 7 Freundlich isotherms for phenol adsorption on activated and natural clay modified montmorillonite at different temperatures

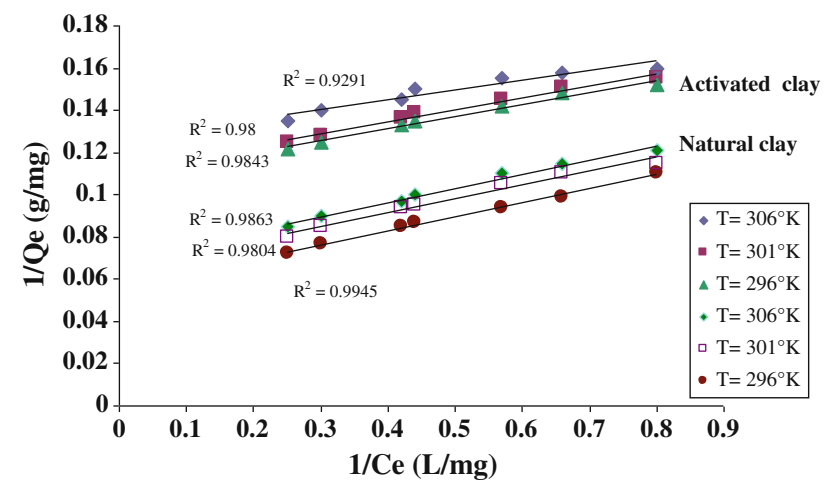

Fig. 8 Longmuir isotherms for phenol adsorption on activated and natural clay at different temperatures

Table 1 Langmuir and FreundHch constants for adsorption of phenol on activated and natural clay at different temperatures

\begin{tabular}{|c|c|c|c|c|c|c|}
\hline & \multicolumn{3}{|c|}{ Lungmuir constants } & \multicolumn{3}{|c|}{ Freundlich constants } \\
\hline & $\begin{array}{l}Q_{\max } \\
(\mathrm{mg} / \mathrm{g})\end{array}$ & $\begin{array}{l}K_{\mathrm{L}} \\
(\mathrm{L} / \mathrm{mg})\end{array}$ & $R^{2}$ & $\begin{array}{l}K_{\mathrm{F}} \\
(\mathrm{L} / \mathrm{mg})\end{array}$ & $1 / n$ & $R^{2}$ \\
\hline \multicolumn{7}{|c|}{ Natural clay at PH5 } \\
\hline$T=296 \mathrm{~K}$ & 11.095 & 1.170 & 0.9291 & 0.589 & 0.4 & 0.9481 \\
\hline$T=301 \mathrm{~K}$ & 9.107 & 0.849 & 0.98 & 0.381 & 0.73 & 0.9679 \\
\hline$T=306 \mathrm{~K}$ & 7.630 & 0.508 & 0.9843 & 0.271 & 0.98 & 0.9791 \\
\hline \multicolumn{7}{|c|}{ Activated clay at PH5 } \\
\hline$T=296 \mathrm{~K}$ & 18.86 & 1.710 & 0.9863 & 0.703 & 0.266 & 0.9759 \\
\hline$T=301 \mathrm{~K}$ & 15.47 & 0.970 & 0.9804 & 0.574 & 0.420 & 0.9914 \\
\hline$T=306 \mathrm{~K}$ & 12.51 & 0.568 & 0.9945 & 0.456 & 0.594 & 0.9581 \\
\hline
\end{tabular}

the presence of high energetic sites were the molecules of phenol were adsorbed (Bras et al. 2005). After the point of inflection of the experimental data, the Freundlich isotherm predicted that the equilibrium adsorption capacity should keep increasing exponentially with increasing equilibrium concentration in the liquid phase. However, the
Table 2 Chemical analyses of material clays of Roussel from Maghnia, N. W. Algeria

\begin{tabular}{llll}
\hline Samples & $\begin{array}{l}\text { Clay of } \\
\text { Roussel } \\
\text { from Maghnia }\end{array}$ & $\begin{array}{l}\text { Maghnia } \\
\text { R.M. }\end{array}$ & $\begin{array}{l}\text { Nord }_{\mathrm{a}} \\
\text { Montmorillonite } \\
\text { family }\end{array}$ \\
\hline $\mathrm{SiO}_{2}$ & $54.10-54.98$ & 55 & $50.04-57.49$ \\
$\mathrm{Al}_{2} \mathrm{O}_{3}$ & $18.04-19.02$ & 24.3 & $17.15-20.27$ \\
$\mathrm{TiO}_{2}$ & $0.14-0.16$ & 0.10 & $0.12-0.48$ \\
$\mathrm{P}_{2} \mathrm{O}_{5}$ & $<0.05$ & 0.02 & - \\
$\mathrm{Fe}_{2} \mathrm{O}_{3}$ & $1.98-2.94$ & 2 & $0.5-5.65$ \\
$\mathrm{CaO}$ & $1.05-2.95$ & 0.98 & $0.23-4.9$ \\
$\mathrm{MgO}$ & $0.11-2.65$ & 3.58 & $0.23-7.2$ \\
$\mathrm{MnO}$ & 2.49 & - & - \\
$\mathrm{Na} 2 \mathrm{O}$ & $0.86-2.40$ & 0.70 & $\mathrm{Tr}-1.32$ \\
$\mathrm{SO}_{3}$ & 0.1 & 0.10 & - \\
$\mathrm{K}_{2} \mathrm{O}$ & $1.14-1.21$ & 1.06 & $0.28-1.27$ \\
\hline
\end{tabular}

experimental adsorption isotherm for phenol presented a long plateau at higher equilibrium concentrations, implying the presence of a monolayer. Thus, Freundlich model should not be used for extrapolation of this data to higher concentrations.

Langmuir model (Eq. 5) gave a better fit at higher concentrations (Fig. 7) with a determination coefficient of $R^{2}=0.994$, implying the formation of a monolayer at higher concentrations, however, the deviation of this model at low equilibrium concentrations implies that the sites of adsorption on the surface of the adsorbent are heterogeneous.

For comparison, the parameter constants for adsorption of phenol on activated clay are also listed in Table 2. Based on values of correlation coefficient, $R^{2}$, the adsorption of phenol was best fitted by Langmuir model. In addition, it is clearly seen that the adsorption capacity, $\mathrm{Q}_{\max }(\mathrm{mg} / \mathrm{g})$ for adsorption of phenol on activated clay was significantly higher than adsorption on natural clay.

Besides, the values of Freundlich constant $K_{\mathrm{F}}$ which has been taken as an indicator of adsorption capacity, was also greater for adsorption of phenol on activated clay as compared to the adsorption on natural clay.

However, natural clay still shows its feasibility and is a promising adsorbent since it is abundantly available and cheaper than commercial activated carbon. Basically, a good adsorption by activated natural clay could be explained by its high surface area additionally (Wu et al. 2001).

\section{Adsorption equilibrium}

\section{Effect of contact time}

The results show that the equilibrium time required for the adsorption of phenol on all samples is about $5 \mathrm{~h}$ as 
illustrated in Fig. 9. The result also indicates that used adsorbents would require less residence time for the complete removal of phenol (Halouli and Drawish 1995).

Natural and activated clay were considered fast because of a rapid increase of adsorbates adsorbed were occurred at the $180 \mathrm{~min}$. Previous findings on the adsorption of phenolic compounds by various clay-based adsorbents have shown a wide range of adsorption time (Song and Sandi 2001).

Therefore, the result in this present study is in agreement with the other reported findings. Up to 70 and $60 \%$ of phenol, was successfully adsorbed by activated and natural clay from the aqueous solution. This proves the feasibility of activated natural clay as an effective adsorbent. (Tahani et al. 1999; Giles et al. 1960).

Values of Freundlich constants are depicted in Table 1. Since the value of $1 / n$ is less than 1 , it indicates favorable adsorption. A smaller value of $1 / n$ indicates better

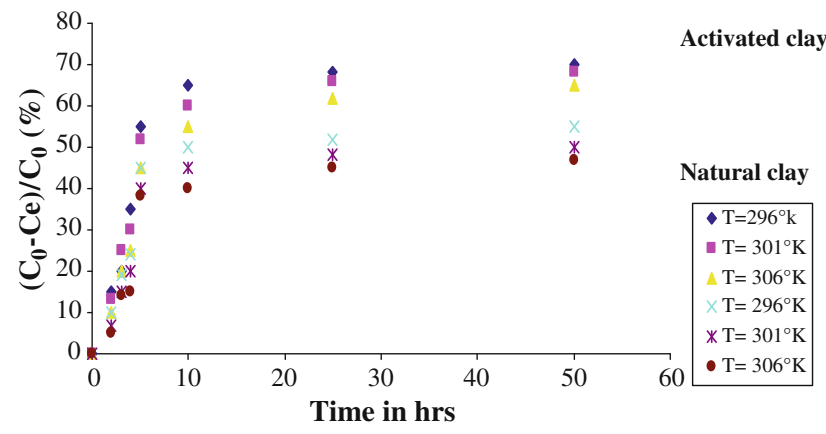

Fig. 9 Effect of time on phenol adsorption

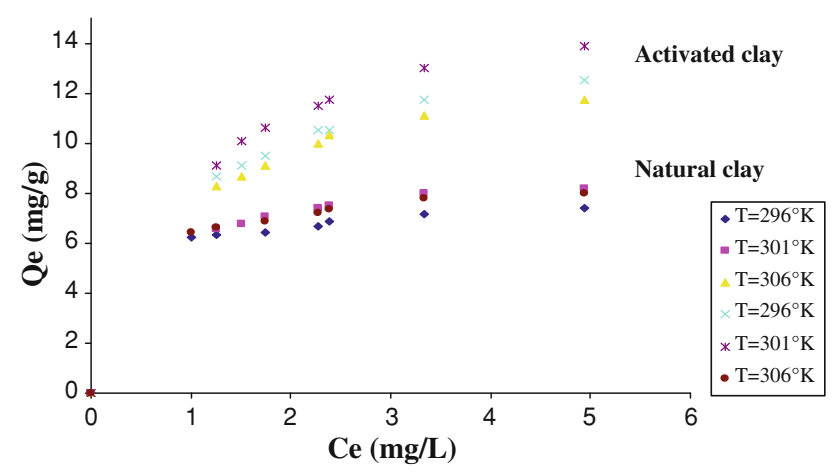

Fig. 10 Sorption isotherm of phenol on natural and activated clay adsorption mechanism and formation of relatively stronger bond between adsorbate and adsorbent (Patil et al. 2006).

Isotherm data reveal that the adsorption process follows both Freundlich and Langmuir isotherm and that the adsorption is favorable. The Langmuir equation and Freundlich model described the isotherm phenol sorption with high correlation coefficient $\left(R^{2}>0.98\right)$. According to Langmuir equation the maximum capacity of phenol sorption $(\mathrm{Qm})$ was obtained as 18.86 and $11.09 \mathrm{mg} / \mathrm{g}$. The applicability of the Langmuir isotherm indicates good monolayer coverage of on the surface of the activated and natural clay (Goyne et al. 2002). The decrease in $K$ (Langmuir constant) values for Langmuir with the rise in temperature indicates weakening of adsorbate-adsorbent interactions at high temperature. It reveals that the adsorption affinity of phenol decreases with the rise in temperature. So adsorption is less favorable at high temperature.

Figure 10 shows an expanded view of the adsorption isotherm of phenol in the range of $0-5 \mathrm{ppm}$, to show in detail the initial section of the isotherm. This figure shows a sigmoidal (S-shape) that reached a long plateau as the concentration increased. This isotherm can be classified as an $\mathrm{S}$ isotherm under the Giles et al. classification system (Rengaraj et al. 2002a, b) (cooperative adsorption) based on the initial shape of the isotherm. According to this classification, in $\mathrm{S}$ isotherms the more molecules of adsorbate are already adsorbed, the easier it is for additional amounts of adsorbate to become fixed to the surface of the adsorbent. This implies a side-by-side association between adsorbed molecules, helping to hold them to the surface and consequently making more stable the adsorbed layer. Molecules of adsorbate that show an S-shape isotherm (as in the case of phenol), are considered monofunctional, where the attraction towards the surface of the adsorbent arises from its $\mathrm{OH}$ group, giving an arrangement of adsorbed molecules oriented perpendicularly to the surface. Under the experimental adsorption conditions, the $\mathrm{pH}$ was in the range of 5-6, below the $\mathrm{pKa}$ of phenol $(\mathrm{pKa}=9.89)$ (Tables 2,3) and below the $\mathrm{pKa}$ for silica $(\mathrm{p} K \mathrm{a}=9.42)$, therefore the phenol and the silanol groups of the surface of the adsorbent, were in a protonated form, making possible that the molecules of phenol were adsorbed onto the surface silanol groups through hydrogen bonds as illustrated in the Fig. 8. This mechanism is similar

Table 3 Characteristic of the selected adsorbate

\begin{tabular}{lllllll}
\hline Name & Formula & $\begin{array}{l}\text { Molecular } \\
\text { weight }\end{array}$ & $\begin{array}{l}\text { Henry's constant } \\
\left(\text { bar m }{ }^{3} / \mathrm{mol}\right)^{\dagger}\end{array}$ & $\begin{array}{l}\text { Water solubility } \\
\text { at } 25^{\circ} \mathrm{C}(\mathrm{g} / \mathrm{L})\end{array}$ & Log $\mathrm{K}_{\text {ow }}$ & Observations \\
\hline Phenol & $\mathrm{C}_{6} \mathrm{H}_{6} \mathrm{O}$ & 94 & $4.0 \times 10^{-7}$ & 87 & 1.5 & $\begin{array}{r}\text { Aromatic semivolatile } \\
\text { weak acid, pK }\end{array}$ \\
\hline $\mathrm{a}$ & & & & 9.98
\end{tabular}

$K_{\text {ow }}$ Octanol/water partition coefficient 
to that reported for the adsorption of phenol onto the surface of silica (Khalid et al. 2000) (Fig. 11).

\section{Effect of pH on phenol adsorption}

Since phenol sorption has been reported to be affected by the $\mathrm{pH}$ of the adsorbate (Singh et al. 1994), the adsorption of phenol by natural and activated clay were studied at various $\mathrm{pH}$ values of the phenol solution $(100 \mathrm{~mL}, 5 \mathrm{mg} / \mathrm{L})$. The amount of phenol adsorbed shows a declining trend with higher as well as with lower $\mathrm{pH}$, with maximum removal of phenol (up to almost $100 \%$ by both the adsorbents) at pH 5 (Fig. 12). This reduction of phenol sorption may be because of the suppression by hydrogen ions (at lower $\mathrm{pH}$ ), and hydroxyl ions (at higher $\mathrm{pH}$ ).

\section{Adsorption thermodynamics}

Thermodynamic parameters

The thermodynamic parameters for the adsorption of phenol by natural and activated clay such as the enthalpy

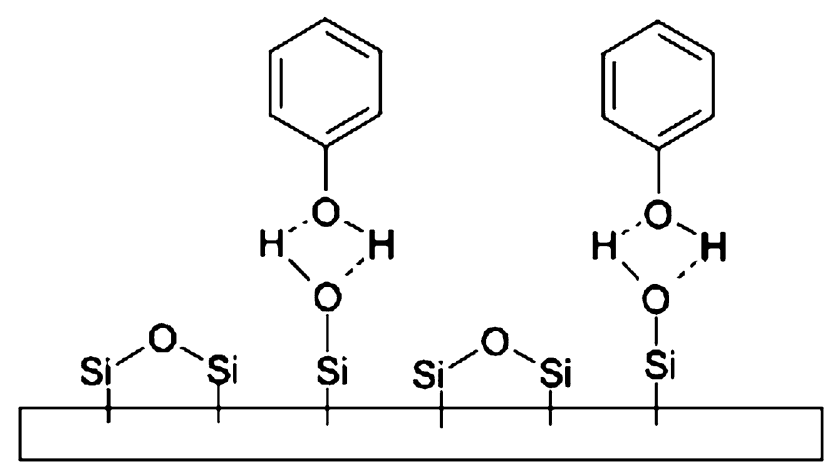

Fig. 11 Proposed adsorption mechanism of phenol molecules onto the surface of natural clay, through hydrogen bonds between $\mathrm{OH}$ group of the phenol and the silanol groups of the clay surface

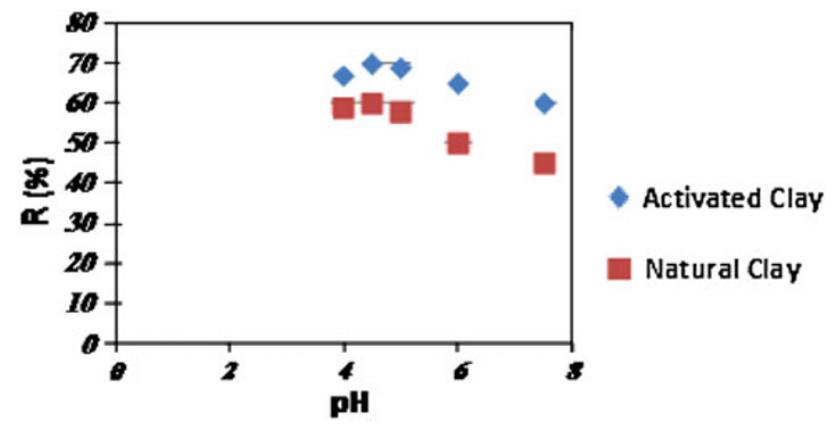

Fig. 12 Effect of pH on phenol adsorption change $\left(\Delta H^{0}\right)$, the Gibbs free energy change $\left(\Delta G^{0}\right)$ and the entropy change $\left(\Delta S^{0}\right)$ can be calculated from the variation of maximum adsorption with temperature $(T)$ using the following basic thermodynamic relations (Seki and Yurdakoç 2006; Al-kaim 2005).

$$
\begin{aligned}
& \ln K_{e}=\frac{\Delta S^{0}}{R}-\frac{\Delta H^{0}}{R T} \\
& \ln K_{e}=-\frac{\Delta G^{0}}{R T} \\
& \Delta S^{\circ}=\left(\frac{\Delta H^{0}-\Delta G^{0}}{T}\right)
\end{aligned}
$$

According to Eq. 7, the mean value of the enthalpy change due do the adsorption of phenol by natural and activated clay over the temperature range studied can be determined graphically by the linear plotting of $\ln \mathrm{K}_{\mathrm{e}}$ against $1 / T$ using the least squares analysis shown in Fig. 5.

\begin{tabular}{|c|c|c|c|}
\hline & \multicolumn{3}{|c|}{ Thermodynamic parameters } \\
\hline & $\begin{array}{l}\Delta H^{0}(\mathrm{~kJ} / \mathrm{mole}) \\
\text { mean value }\end{array}$ & $\begin{array}{l}\Delta \mathrm{G}^{0} \\
(\mathrm{kj} / \mathrm{mole})\end{array}$ & $\begin{array}{l}\Delta S^{0}(\mathrm{~J} / \mathrm{K} \text { mole }) \\
\text { mean value }\end{array}$ \\
\hline \multicolumn{4}{|c|}{ Natural clay at PH5 } \\
\hline$T=296 \mathrm{~K}$ & -1.666 & 3.293 & 5.510 \\
\hline$T=301 \mathrm{~K}$ & & $-3.31]$ & \\
\hline$T=306 \mathrm{~K}$ & & -3.340 & \\
\hline \multicolumn{4}{|c|}{ Activated clay at PH5 } \\
\hline$T=296 \mathrm{~K}$ & -1.331 & -2.1611 & 4.339 \\
\hline$T=301 \mathrm{~K}$ & & -2.632 & \\
\hline$T=306 \mathrm{~K}$ & & -2.652 & \\
\hline
\end{tabular}

Table 4 The thermodynamic parameters for the adsorption of phenol on natural and activated clay

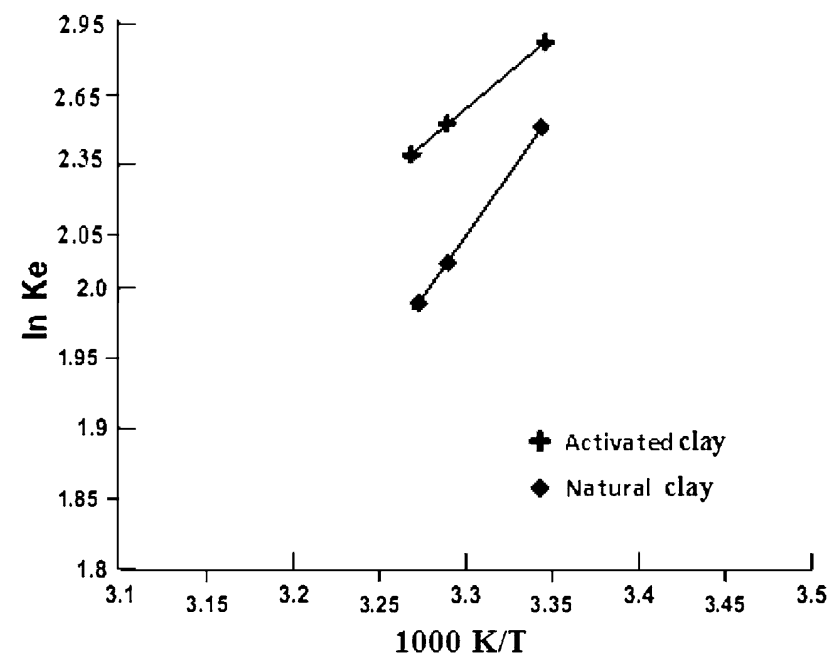

Fig. 13 Van't Hott equation for adsorption of phenol on activated and natural clay at different temperatures 
A

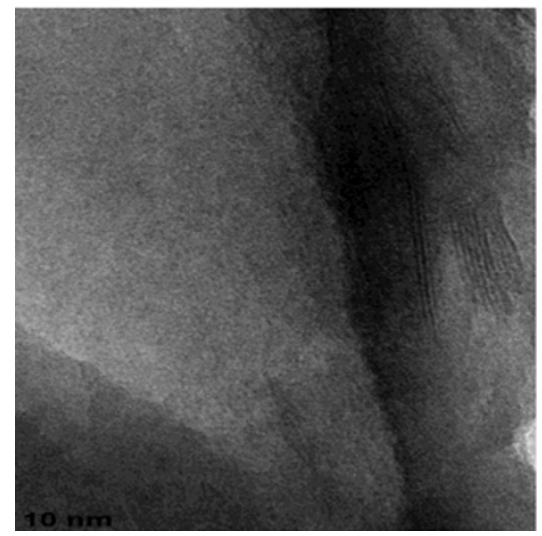

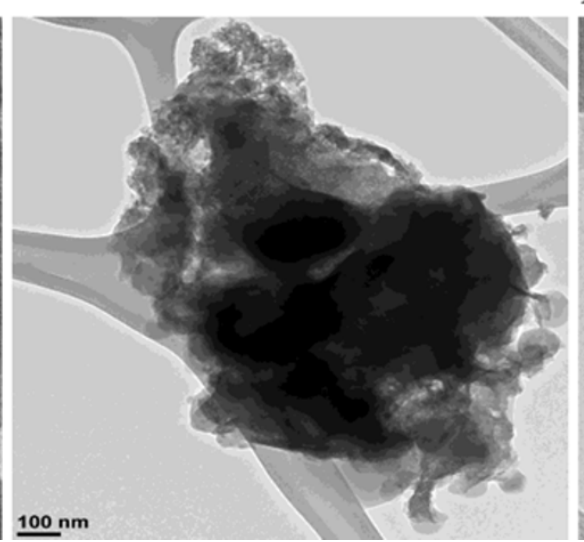

B

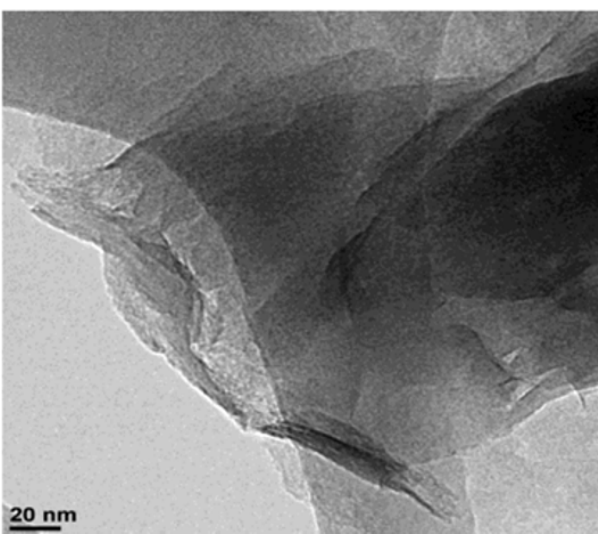

Fig. 14 Transmission electron microscopy (TEM) picture

The mean enthalpy change can be determined from the slope of the straight line. The variation of Gibbs free energy and entropy change with temperature can be calculated using Eqs. 8 and 9, respectively, the results are arranged in Table 4.

An important result can be obtained from Table 4 is that the Gibbs free energy $\left(\Delta G^{0}\right)$ is small and negative with its value decreasing with increasing temperature. This indicates that the adsorption processes of phenol by natural and activated clay can be enhanced by decreasing temperature. The values of entropy change $\left(\Delta S^{0}\right)$ are positive and remain almost constant with temperature. This gives an evidence that structural changes in phenol and natural and activated clay occur during the adsorption process (Fig. 13)

The negative values of enthalpy change $\left(\Delta \mathrm{H}^{0}\right)$ for the adsorption is lower than $80 \mathrm{~kJ} \mathrm{~mol}^{-1}$, suggesting the physical nature of the sorption, i.e., physisorption conducted with van der Waals forces.

The enthalpy change $\left(\Delta \mathrm{H}^{0}\right)$ of the adsorption is -1.666 and $-1.333 \mathrm{~kJ} / \mathrm{mol}$ indicating physical adsorption of phenol on to natural and activated clay (Seki and Yurdakoç 2006). The overall adsorption process seems to be exothermic.

The TEM micrograph of purified clay is shown in Fig. 14 It shows the laminated clay layers and the average thickness of pristine layers varies from 20 to $100 \mathrm{~nm}$, a characteristic property of nanoclay. These micrographs show the formation of nanoclays. The TEM images also support the XRD results.

The difference between activated clay and the natural clay was most clearly seen when the clays were examined by TEM. Figure 12 shows electron micrographs of a sample of natural and activated clay. At low magnification (Fig. 14a), two types of particles, small dark rectangular particles embedded in much more numerous large fibrous particles, can be seen. TEM analysis showed that the small dark rectangular particles were silicate impurities.
Figure 14b shows a high magnification picture of one of the fibers. The edges of the clay layers are very clearly seen. The spacings between the layers were of the order of $12.11 \AA$.

\section{Conclusion}

Natural clay was a potential and promising adsorbent for removal of phenolic compounds from aqueous solution. The results were compared with activated clay. The adsorption of phenol on activated clay was higher than adsorption on natural clay. However, Natural clay stands as low-cost adsorbent and it shows the feasibility to remove up to $60 \%$ of phenol, for initial concentration.

The Langmuir equation agrees very well with the equilibrium isotherm also Freundlich equation give accepted linearity. Finally, the adsorption of phenol on the natural clay surface is exothermic. The results revealed that the natural clay can be employed as adsorbent for treatment of aqueous waste streams.

Acknowledgments The authors would like to thank the University of Technology Faculty of Chemistry, Oran, Algérie and Mascara's laboratory University. The authors thank also Prof. F.djafri for her assistance in XRD and IR measurements and educational experience, without forgetting Prof. A. Djafri for her helpful discussions. Finally, the authors offer a special thanks to Prof. M. Bouchekara for his guidance and support throughout of this research.

Open Access This article is distributed under the terms of the Creative Commons Attribution License which permits any use, distribution, and reproduction in any medium, provided the original author(s) and the source are credited.

\section{References}

Aghamohammadi N, Hamidi AA, Hasnain IM, Zinatizadeh AA, Nasrollahzadeh Saravi H, Ghafari Sh (2007) Performance of a 
powdered activated carbon (pac) augmented activated sludge process treating semi-aerobic leachate. Int $\mathrm{J}$ Environ Res 1:96-103

Al-kaim A (2005) Synthesis and characterization $\mathrm{f}$ zeolite- urea formaldehyde polymer complex and study of adsorption of some phenolic compounds from aqueous solution on it's surface, M.Sc Thesis, College of Science, University of Babylon

Alkaram UF, Mukhis AA, Al-Dujaili AH (2009) The removal of phenol from aqueous solutions by adsorption using surfactantmodified bentonite and kaolinite. J Hazard Mater 169:324-332

Annadurai G, Rajesh Babu S, Mahesh KPO, Murugesan T (2000) Adsorption and biodegradation of phenol by chitosan-immobilized Pseudomonas putida (NICM 2174). Bioprocess Eng 22:493-501

APHA, AWWA, WEF (2006) Standard methods for the examination of water and wastewater, XX edn. APHA, Washington

Aygiin A, Karakag SY, Duman I (2003) Production of granular activated carbon from fruit stones and nutshells and evaluation of their physical, chemical and adsorption properties. Microporous Mesoporous Mater 66:I89-I95

Bras I, Lemos LT, Alves A, Pereira MR (2005) Sorption of pentachlorophenol on pine bark. Chemosphere 60:1095-1102

Denizli A, Cihangir N, Ttizmen N, Alsancak G (2005) Removal of chlorophenols from aquatic systems using the dried and dead fungus Pleurotus sajor caju. Bioresour Technol 96:59-62

Freundlich H (1926) Colloid and Capillary Chemistry. Matheun and Co, London

Gadsden A (1975) Infrared spectra of minerals and related inorganic compounds. The Butterworth group, UK

Giles CH, Nakhwa SN (1962) Studies on adsorption. Part XVI areas of finely divided solids by solution adsorption. J Appl Chem 12:266-273

Giles CH, Mac Ewan TH, Nakwa SN, Smith D (1960) Studies in adsorption. Part XI.* A system of classification of solution adsorption isotherms, and its use in diagnosis of adsorption mechanisms and in measurement of specific surface areas of solids. J Chem Soc 3:3973-3993

Goyne KW, Zimmerman AR, Newalkar BL, Komarneni S, Brantley SL, Chorover J (2002) Surface charge of variable porosity $\mathrm{Al}_{2} \mathrm{O}_{3}(\mathrm{~s})$ and $\mathrm{SiO}_{2}(\mathrm{~s})$ adsorbents. J Porous Mat 9:243-256

Haggerty GM, Bowman RS (1994) Sorption of inorganic anions by organo-zeolites. Environ Sci Technol 28:452-458

Hajjaji M, Kacim S, Alami A, El-Bouadili A, El Mountassir M (2001) Chemical and mineralogical Characterization of a clay taken from the Moroccan Meseta and a study of the interaction between its fine fraction and methyleneblue. Appl Clay Sci 20:1-12

Hall KR, Eagleton LC, Acrivos A, Vermeulen T (1996) Pore-and solid- diffusion kinetics in fixed-bed adsorption under constantpattern conditions. Ind Eng Chem Fundam 5:212-223

Halouli KhA, Drawish NM (1995) Effects of $\mathrm{pH}$ and inorganic salts on the adsorption of phenol from aqueous systems on activated decolorizing charcoal. Sep Sci Technol 30:3313

Hassani AH, Seif S, Javid AH, Borghei M (2008) Comparison of adsorption process by GAC with novel formulation of coagulation: flocculation for color removal of textile wastewater. Int J Environ Res 2(3):239-248

Ibrahim HG, Abushina EA (2008) Investigation on the removal of chromium (III) from tannery wastewater by cement kiln dust. J Ass Arab Univ Basic Appl Sci 5:59-71

Juang R-S, Lin S-H, Tsao K-H (2002) Mechanism of sorption of phenols from aqueous solutions onto surfactant-modified montmorillonite. J Colloid Interface Sci 254-234

Khalid N, Ahmad S, Toheed A (2000) A potential of rice husk for antimony removal. Appl Radiat Isotopes 52:30-38

Kumar A, Kumar S, Kumar S, Gupta DV (2007) Adsorption of phenol and 4- nitro phenol on granular activated carbon in basal salt medium: equilibrium and kinetics. J Hazard Mater 147:155-166

Langmuir I (1918) Adsorption of gasses on plane surfaces of glass, mica and platinum. J Am Chem Soc 40:1361-1403

Lin SH, Cheng MJ (2002) Adsorption of phenol and m-chlorophen on organobentonites and repeated thermal regeneration. Waste Manage 22:595-603

Madejova 'J (2003) FTIR techniques in clay mineral studies. Vibrational Spectroscopy 31:1-10

Patil S, Bhole A, Natrajan G (2006) Scavenging of Ni(II) metal Ions by adsorption on PAC and Babhul Bark. J Environ Sci Eng 48(3):203-208

Pusino A, Micera G, Gessa C, Petretto S (1989) Interaction of diclofop and diclofop-methyl with $\mathrm{Al} 3+, \mathrm{Fe} 3+$, and $\mathrm{Cu} 2+$ saturated montmorillonite. Clays Clay Miner. 37:558-562

Rengaraj S, Seuny-Hyeon M, Sivabalan R (2002a) Agricultural solid waste for the removal of organics: adsorption of phenol from water and wastewater by palm seed coat activated carbon. Waste Manag 22:543-548

Rengaraj S, Moon SH, Sivabalan R, Arabindoo B, Murugesan V (2002b) Removal of phenol from aqueous solution and resin manufacturing industry waste water using as agricultural waste: rubber seed coat. J Hazard Mater B89:185-196

Robert M, Tessier D (1974) Méthode de préparation des argiles des sols pour des études minéralogiques. Ann Agron 25:859-882

Seki Y, Yurdakoç K (2006) Adsorption of promethazine hydrochloride with KSF montmorillonite. Adsorption 12(1):89-100

Singh BK, Mishra NM, Rawat NS (1994) Sorption Characteristics of Phenols on Fly Ash and Impregnated Fly Ash. Indian J Environ Health $36: 1-7$

Song K, Sandi G (2001) Characterization of montmorillonite surfaces after modification by organosilane. Clays Clay Miner 49(2): $119-125$

Tahani A, Karroua M, El Farissi M, Levitz P, van Damme H, Bergaya F, Margulies L (1999) Adsorption of phenol and chlorine derivatives PLICS and organo-PLICS. J Chem Phys 96:464-469

Vianna MMGR, Franco JHR, Pinto CA, Diaz FRV, Büchler PM (2004) Sorption of oil pollution by organoclays and a coal/ mineral complex. Brazil J Chem Eng 21(02):239

Wu PX, Liao II W, Zhang HF, Guo JG (2001) Adsorption of phenol on inorganic-organic pillared montmorillonite in polluted water. Environ Int 26:401-407 